This is an electronic reprint of the original article. This reprint may differ from the original in pagination and typographic detail.

Author(s): Lämsä, Anna-Maija; Heikkinen, Suvi; Smith, Mark; Tornikoski, Christelle

Title: $\quad$ The expatriate's family as a stakeholder of the firm : a responsibility viewpoint

Year: $\quad 2017$

Version:

Please cite the original version:

Lämsä, A.-M., Heikkinen, S., Smith, M., \& Tornikoski, C. (2017). The expatriate's family as a stakeholder of the firm : a responsibility viewpoint. International Journal of Human Resource Management, 28(20), 2916-2935.

https://doi.org/10.1080/09585192.2016.1146785

All material supplied via JYX is protected by copyright and other intellectual property rights, and duplication or sale of all or part of any of the repository collections is not permitted, except that material may be duplicated by you for your research use or educational purposes in electronic or print form. You must obtain permission for any other use. Electronic or print copies may not be offered, whether for sale or otherwise to anyone who is not an authorised user. 
Title page

\title{
The expatriate's family as a stakeholder of the firm: A responsibility viewpoint
}

\author{
Authors: \\ Anna-Maija Lämsäa, Suvi Heikkinen ${ }^{\mathrm{a} *}$ Mark Smith $^{\mathrm{b}}$, and Christelle Tornikoski ${ }^{\mathrm{b}}$ \\ ${ }^{a}$ University of Jyväskylä, Jyväskylä, Finland \\ ${ }^{b}$ Grenoble Ecole de Management, Grenoble, France
}

*Contact address:

Suvi Heikkinen

PhD Student

University of Jyväskylä

School of Business and Economics

Department of Leadership and Management

P.O. Box 35

40014 University of Jyväskylä

Finland

Tel: +358 407459058

E-mail: suvi.s.heikkinen@jyu.fi

* Corresponding author. Email: suvi.s.heikkinen@jyu.fi 


\title{
RESEARCH ARTICLE
}

\section{The expatriate's family as a stakeholder of the firm: A responsibility viewpoint}

\begin{abstract}
In this paper we argue for the recognition of the expatriate's family as a stakeholder of the firm during the expatriation. We demonstrate why the expatriate's family can be regarded as a stakeholder of the parent company and what kind of a stakeholder the family is. Additionally, we argue that the parent company needs to develop and apply a holistic wellbeing orientation to show stakeholder responsibility in the IA arena. We apply the theory of stakeholder salience to the IA relationship because it provides a theoretical framework for integrating the family into the expatriation process. Yet this theory does not necessarily provide a framework for assessing the social functioning of expatriates and their family members. Since expatriation often leads to a radical shift in family roles and living circumstances, family members (or indeed the expatriates themselves) cannot replicate all elements of their previous lives in the host country. Therefore, we use the capabilities approach to complete the theoretical framework, as this approach provides an evaluative mechanism which highlights how a socially responsible relationship between the company and the family can be advanced to foster wellbeing and quality of life for the family members as well as the expatriate, even if their functioning abroad differs from their functioning in their own country.
\end{abstract}

Keywords: expatriation, international assignment, family, work-life relationship, wellbeing, stakeholder, corporate social responsibility, capabilities 


\section{Introduction}

International assignments (IAs) are often considered prerequisites to the development of managerial and professional careers within an organization, and they are also deemed critical to overall corporate strategy. Today organizations are tending to diversify their IAs and the many types of IAs have given rise to the use of different types of expatriates: self-initiated expatriates, international itinerants, global careerists (Suutari and Brewster 2000; Banai and Harry 2004; Siljanen and Lämsä 2009). Still, in this paper we focus on traditional expatriation - the employment model in which an employing company sends its employees to its subsidiaries abroad on a temporary basis (Dowling and Welch 2004), a common way of meeting the need for international work.

It is widely recognized that expatriation and its management involve both opportunities and difficulties for both parties in the employment relationship - the employee (the expatriate) and the employer (the parent company) (Ali, Van der Zee and Sanders 2003; Banai and Harry 2004; Siljanen and Lämsä 2009). According to Takeuchi (2010), prior academic research on expatriation has often aimed at identifying hindrances to the success of expatriation by examining expatriate adjustment. These approaches are open to criticism. First, this stream of research on expatriation has typically focused either on the dyadic relationship between the employee and the employer or solely on the expatriate; and second, despite exceptions (e.g. Lazarova, Westman and Shaffer, 2010; Mäkelä, Suutari and Mayerhofer 2011; Shaffer, Harrison, Gilley and Luk, 2001; Smith and Tornikoski 2012), it has tended to neglect other stakeholders affected by international mobility. In addition research has mainly focused on negative issues, such as the failure of the IA itself.) Indeed Takeuchi (2010) underlines that the fact that many studies have applied the stress perspective, which emphasizes a negative view on expatriation: the high premature return rate and lower performance. Additional theoretical viewpoints are therefore needed in order to advance expatriation research.

Prior research has shown that family concerns represent key challenges for expatriates and play a critical role in the success or failure of the IA and the repatriation (Caligiuri, Hyland, Joshi and Bross 1998; Mäkelä et al. 2011; Shaffer and Harrison 1998). Even if relations between the employee and her/his family tend to be seen as the preserve of the private domain in a national context, this can hardly be the case in an international context. Even though organization-employee relations remain at the heart of the employment relationship, the impact of an expatriate's career on the family becomes very significant in an international context - and vice versa (Dupuis, Haines and Saba 2008; Haslberger and Brewster 2008; Lauring and Selmer 2010; Smith and Tornikoski 2012). For instance, family influence and involvement have been found to be crucial in the decision to accept or reject an expatriate assignment (Brett and Stroh 1995; Dupuis et al. 2008; Harvey 1998). The way in which the family is socialized into and adjusts to the foreign culture also affects the expatriate's work (Haslberger and Brewster 2008). As a result of spillover effects, the stress experienced at work by an expatriate can influence the stress experienced by other family members at home, and vice versa.

The family's role in supporting the expatriate employee during an assignment and the family's interaction with the company are often discussed indirectly via the employee. Moreover, the family's role in the process of negotiating the conditions of expatriation between the employer and the employee is usually seen in an implicit rather than an explicit way by companies. According to Takeuchi (2010), an implicit assumption in expatriation research is often that the focus should be on the expatriates themselves rather than on other parties in their social environment, namely, the family and its members. Thus, research on expatriation has traditionally examined the impact of the family on expatriation and 
repatriation by considering the family as a part of the expatriate's private sphere (Riusala and Suutari 2000), in other words, as external to the expatriation relationship.

In this article we argue for recognition of the expatriate's family as a stakeholder of the firm in the IA arena. According to Freeman (1984), a stakeholder is any individual or group that can affect or be affected by the actions, decisions, policies, practices or goals of the company. Expatriation can be considered a multi-party relationship in which not only employees (expatriates) but also their families are stakeholders of the parent organization in the context of IAs. According to Takeuchi (2010), even though there are studies which examine the impact of other stakeholders, such as the family, on expatriates, there are few studies in expatriation research that take into account the effect of expatriation on stakeholders such as the family and its members. Moreover, consideration is rarely given to the relationship between the company and the family itself. Thus, this paper broadens the focus to include explicitly the family of the expatriate.

We argue that the expatriate's family can be regarded as a stakeholder of the parent company and propose what kind of a stakeholder the family is. Our aim is to build a theoretical framework and develop propositions that will enable empirical study of the expatriate's family as a stakeholder of the firm. For this purpose, we apply the theory of stakeholder salience (Mitchell et al. 1997). This theoretical approach allows an examination of the conditions under which the expatriate's family can be considered a stakeholder of the company. In particular, Mitchell and colleagues (1997) argue that the theory enables a descriptive approach to explain the relationship between a company and a stakeholder group. They claim that the strength of the theory is that it contributes to highlighting stakeholder salience and its dynamism as opposed to static maps of a company's stakeholder environment.

This paper also builds specifically upon the ideas of Takeuchi (2010), who adopted a stakeholder viewpoint to expatriate adjustment and showed the importance of the influence of other stakeholders (family, parent company, host country nationals) on expatriates. However, Takeuchi (2010) focused on the relationship between the expatriate and other stakeholders, not explicitly on the relationship between the company and the expatriate's family, as in this study. In other words, this study takes another perspective and focuses specifically on the dynamism between the company and the expatriate's family. The stakeholder salience theory (Mitchell et al. 1997) provides a theoretical framework for integrating the employee's family into the expatriation process. This integration recognizes the role of family members as stakeholders of the company; yet it does not necessarily provide a framework for assessing the relationship and the social functioning of family members. It is here that the capabilities approach (Sen 1985) can have an important contribution to make.

Based on the capabilities approach (Sen 1985) we argue that the parent company needs to develop and apply a holistic wellbeing orientation in order to show stakeholder responsibility in the IA arena. Since expatriation often leads to a radical shift in family roles and living circumstances, family members (or indeed the expatriates themselves) cannot replicate all elements of their previous lives in the host country. Therefore, we combine the theory of stakeholder salience (Mitchell et al. 1997) with the capabilities approach (Sen 1985). The capabilities approach complements stakeholder theory by providing an evaluative mechanism which highlights how a socially responsible relationship between the company and the family can be advanced through HRM practices to foster wellbeing and quality of life for the family members (as well as the expatriate), even if their functioning abroad differs from that which they adopt in the domestic employment context. Considering the family (and its members) as a stakeholder allows for examination of the family's expectations with regards to the company's support, of the ways in which the family articulates its expectations, 
and of the response of the organization to these expectations. For this reason we argue for a capabilities approach to complement the notion of the family as a dynamic stakeholder.

One key strength of the capabilities approach is that it justifies explicitly the ethical position of company responsibility. Thus, the capabilities approach offers a wider viewpoint by acknowledging that the stakeholder relationship between the company and the expatriate's family is broader than just an instrumental or financial one. The ethical perspective gives new insight on the desired HRM outcomes and, consequently, advances discussion about socially responsible HRM practices (Kramar 2014). Developed by Sen (1985), the capabilities approach was initially concerned with the distribution of opportunities within society. By highlighting the materialistic and non-materialistic aspects of human welfare, the importance of freedoms in assessing personal advantage and the existence of differences in individual abilities to transform resources into valuable activities. For this study, the capabilities approach provides a useful framework for assessing the family-member outcomes.

The combination of the stakeholder salience (Mitchell et al. 1979 and capabilities approaches (Sen 1985) permits an extension of expatriation research. Specifically, this combination helps to broaden the traditional perspective, which focuses either on the dyadic relationship between the expatriate and the company or on the expatriate her- or himself. From a practical perspective, considering the expatriate's family as a stakeholder provides the advantage of recognizing its role in HRM practices such as corporate recruitment decision as well as its crucial role in supporting or challenging the expatriate's career and goal achievement whilst abroad. Such a view also renders the role, interests and expectations of the family visible. Considering the family as a stakeholder could be an opportunity for the development of fruitful ideas and HRM practices in the field of expatriation and IAs in general. Such a perspective can help companies to align their strategic business goals, which focus on performance, with their social responsibilities. While paying more attention to the work-family relationship and the expectations of the expatriate's family offers a way to develop socially responsible behaviour. In general, the importance of corporate social responsibility has risen steadily, and companies have found it necessary to develop initiatives and programs of responsible behaviour (Crane and Matten 2010; Midttun, Gautesen and Gjølberg 2006).

\section{The stakeholder salience approach}

The employment relationship both in the national and the international context has been examined mainly from a dyadic perspective, with the organization on one side and its employees on the other (Takeuchi 2010). Relations between the individual and her/his family are important for the individual's non-work life, but they are typically not considered in the context of the employment relationship. In the context of IAs, organizational-individual relations remain at the heart of the employment relationship, but the link between an individual's work and her or his family becomes much more significant. Thus, from the company's point of view it becomes important to regard the expatriate's family as a stakeholder of the company.

Stakeholder theory conceptualizes the company as embedded in a series of groups and individuals with different respective relationships to it (Schneider 2002). The company has a range of different stakeholders, who have divergent expectations of and interests in it (Donaldson and Preston 1995). A stakeholder has been defined by Freeman (1984, p. 46) as "any group or individual who can affect or is affected by the achievement of the organization's objectives". Stakeholders can include internal organizational members, such as employees, and external members, such as customers, suppliers (Schneider 2002), and employees' families (Takeuchi 2010). 
Even though the stakeholder approach has become popular among researchers and practitioners of both management and organization there is no agreement on who the stakeholders of the company are (Freeman et al. 2010; Mitchell et al. 1997). Many individuals and groups can be viewed as stakeholders (Kujala 2010; Näsi 1995), and management is likely to consider some stakeholders important and others less so. Balancing the expectations and interests of many different stakeholders can be seen as an integral part of organization management. Hill and Jones (1992) propose that each stakeholder is part of the nexus of explicit and implicit contracts that constitutes the firm, and management as a group is at the center of this nexus. Management is the only group of stakeholders who deal with all other stakeholders and control the decision-making of the company (Hill and Jones 1992, p. 134). Therefore, their role is at the heart of stakeholder theory.

The theory of stakeholder salience allows us to identify why the expatriate's family can be regarded as a stakeholder of the parent company in the context of IAs. According to this theory, stakeholder relations are dynamic and can change in salience (Mitchell et al. 1997). Mitchell and colleagues (1997) suggest that three attributes - power, urgency and legitimacy - are of importance when a company and its management are making decisions regarding who their stakeholders are and why. Stakeholders as well as their salience to the company can be identified based on the possession or attributed possession of one, two or all three of the attributes (Mitchell et al. 1997). Mitchell and colleagues (1997) argue that the stakeholder-company relationship needs to be understood in terms of the relative presence or absence of all or some of the attributes. Consequently, the expatriate's family can be regarded as a stakeholder of the parent company in the context of IAs whenever the management perceives that the family of the company's employee possesses one or more of the attributes - power, urgency and legitimacy - that affect the family's relationship with the company. Consequently, we make the following proposition:

Proposition 1: The salience of the expatriate's family as a stakeholder increases when the management of the parent company perceives and recognizes its stakeholder attributes in the relationship between the company and the family.

Next we discuss the attributes and roles of the expatriate's family in its relationship with the company in greater detail.

\section{Power}

Power is said to exist in a stakeholder relationship when a stakeholder, such as the expatriate's family, can get the firm to do something that it may not have otherwise done Etzioni (1964) offers a synthesis of different sources of power in organizational life. Drawing on this classification, Mitchell et al. (1997) contend that power in a stakeholder relationship is based on the types of resources that parties use to influence or exercise pressure on each other. They argue that a party in a relationship has power depending on the extent to which it has or can gain access to different types of resources to impose its will in the relationship.

Etzioni (1964) distinguishes three types of power, namely, coercive, utilitarian and normative. Coercive power is based on force, restraint or even violence. According to Etzioni (1964), even the threat of coercive power is considered influential, since its effect on the subject is similar to the real use of coercive power. The use of coercive power typically creates negative outcomes, such as dislike, anger, alienation, dissatisfaction and conflict among parties. In the context of IAs, coercive power can be seen when the expatriate's family applies some kind of constraining force on the parent company in the expatriation process. Based on previous studies of expatriation, we suggest that the expatriate's family possesses 
some coercive power on the organization, since many factors and issues related to the family can affect the company's expatriate recruitment and career management in a negative and constraining way (e.g. Brett and Stroh 1995; Dupuis et al. 2008; Shaffer and Harrison 1998; Suutari et al. 2012). For example, Suutari and colleagues (2012) showed that expatriates' families had decisive influence on the expatriates' refusal of external job offers and also weighed heavily on the expatriates' demotivation of repatriating especially in terms of employer change or international assignments. This supports the findings of Shaffer and Harrison (1998), who discovered that the more family responsibilities an expatriate employee had, the more salient were family-related factors in the decision to withdraw from the IA. In addition, Dupuis and colleagues (2008) showed that a negative predictor of spousal willingness to relocate internationally for periods of less than one year was many spouses' fear of jeopardizing their careers or jobs for a relatively short sojourn overseas. Tharenou (2008) found that family factors can affect negatively employees' willingness to expatriate. Previous research also highlights how often an IA is discontinued because of family issues and problems related to the family's adjustment abroad (e.g. Ali et al. 2003; Shaffer and Harrison 1998; Takeuchi 2010; Takeuchi, Yun and Tesluk 2002). In sum, as highlighted above, many previous results imply that the expatriate's family can have a constraining effect on the parent company, since the company may lose the expatriate's competencies and resources if expatriation is rejected or discontinued by him or her for family reasons. To try to overcome the problem the company can develop HRM practices that help the family to cope with and live in a foreign environment. Examples of such HRM practices could be logistical and housing support for the family, the training and mentoring of spouses and children to integrate socially and culturally into the new environment, help to spouses in finding suitable employment, and company childcare so that spouses have the chance to work when they wish to do so.

Utilitarian power is based on material or non-material benefits that parties receive in a relationship (Etzioni 1964). The use of utilitarian power typically results in an instrumental relationship in which parties consider each other useful and valuable for their benefits and goals. From this utilitarian perspective, the stakeholder relationship between the expatriate's family and the parent company is instrumental. Previous research supports this: it has shown that management can view the expatriate's family as providing some benefits to the parent company and as acting in ways that are beneficial to the company. For instance, the study of Lazarova, Westman and Shaffer (2010) demonstrates that the adjustment of the expatriate's partner to her or his new role in the host country can be a source of satisfaction and motivation for the expatriate, which can in turn contribute to the expatriate's effectiveness in her/his role in the company. According to the enrichment approach to the relationship between work and family (Greenhaus and Powell 2006), when the expatriate is energized in both familial and professional roles, her/his goal achievements in both work and family contexts are improved during the expatriation, which can make a positive contribution to organizational performance (Paauwe and Richardson 1997). Moreover, the interplay of work and family has been shown to influence the likelihood of expatriates' successful completion of their assignments, and family considerations play an important role in the success of repatriation (Lauring and Selmer 2010; Mäkelä et al. 2011; Riusala and Suutari 2000; Shaffer et al. 2001). Therefore, seen from the viewpoint of HRM the family affects the decisions of the company's career management and recruitment by supporting the employee's decision to expatriate and by supporting the employee's career through expatriation and repatriation.

Finally, according to Etzioni (1964), normative power refers to symbolic resources such as ideals, prestige, esteem and acceptance. In particular, this form of power is derived through common ideals, goals and values in a stakeholder relationship. Thus, to have normative power the expatriate's family needs to share common values and goals with the 
parent company. The family can be argued to possess normative power whenever there is a fit between the goals of the two parties. In the case of an international assignment, both the family and the organization can be considered to hold the goal of the expatriation's success. Given that prior research (e.g. Ali et al. 2003; Mäkelä et al. 2011; Schaffer and Harrison 1998) has shown that the decision to expatriate is critical in many ways to the whole family, it seems plausible to conclude that the success of the expatriation can be (is) a goal shared by both the family and the organization. From the viewpoint of HRM practices this suggests that it would be fruitful to set up channels for communication and information sharing between the company and the expatriate's family to clarify their common goals.

\section{Urgency}

According to Mitchell et al. (1997), urgency refers to the degree to which stakeholder claims call for immediate attention. Consequently, urgency is a stakeholder attribute which relates specifically to the dynamic nature of the stakeholder relationship. Urgency underlines the idea that the company needs to pay attention in a timely fashion to the stakeholder's attributes, such as particular needs related to the relationship. In the context of IAs this means that the salience of the family as a stakeholder varies during the expatriation process and during transition periods (before and after expatriation).

Urgency exists when the company-family relationship involves time sensitivity. Delay on the part of the company in attending to the claims and expectations of the expatriate's family can be problematic. Prior academic research on cross-cultural adjustment shows that adapting to a new cultural environment is a challenging process for people (e.g. Black, Mendenhall and Oddou 1991; Bennett and Bennett 2004; Kim 2001). In Kauppinen's (1994) study, the adjustment of an expatriate's family or spouse was specifically mentioned as a factor facilitating the expatriate's own adjustment and thus her/his chances of a successful assignment abroad (see also Takeuchi 2010). Mäkelä et al. (2011) argue that an IA that involves the international relocation of the family will have an extensive impact on the whole family - not only on the expatriate. In particular, the issue of culture shock has been found to be important in the process of cross-cultural adjustment. Culture shock has been traditionally linked to distress and emotional reactions experienced by individuals as a result of losing their familiar signs and symbols of social interaction and of misinterpreting experiences in an unfamiliar cultural environment (Oberg 1958). Culture shock describes the unpleasant or negative experiences in intercultural encounters. Even though there are several models of culture shock (e.g. Adler 1975; Hofstede 1991; Oberg 1958; Ward, Bochner and Furnham 2001), all of them identify confusion, anxiety, disorientation and stress as potential results of this shock, especially at the early stages of the adaptation process. They can be reduced or overcome through cross-cultural development and training (e.g. Black et al. 1991; Bennett and Bennett 2004; Kauppinen 1994; Kim 2001). This challenge requires the parent company's HR practices to respond to the family's (and the expatriate's) need for crosscultural training in a timely fashion, in particular at the beginning of the expatriation process and when repatriating, when a so-called reverse culture shock can occur (Black et al. 1991). Thus, the organization needs to pay particular attention to the urgency of the family's needs at turning points or moments when cultural adaption becomes critical and when perceptions of uncertainty typically occur.

In addition to time sensitivity, urgency is related to criticality, which refers to the importance of the claim to the stakeholder (Mitchell et al. 1997). Mitchell et al. suggest several examples of a stakeholder's critical claims. For example, ownership is linked to the stakeholder's possession of resources tied to the company that cannot be used in a different way without loss of value (Hill and Jones 1992). In other words, it is costly for the 
stakeholder to exit the relationship. Sentiment is associated with the emotional value of the relationship for the stakeholder, while an expectation is the stakeholder's anticipation that the company continues to provide her/him/it with something of great value, such as benefits. Finally, exposure is another facet of critical claims, and it relates to the importance that the stakeholder attaches to what is at risk in the relationship with the company. In general, previous research (e.g. Claus, Lungu and Bhattacharjee 2011; Nie and Lämsä 2015) has shown that there are certain specific factors which increase challenges and problems in cultural adaption. These factors can be considered especially critical to the family's adaptation. Claus and colleagues (2011) propose that cultural distance and institutional distances, for example, are critical factors in culture shock. Cultural distance refers to the difference between the "host" and "home" cultures (Claus et al. 2011). While institutional distance refers to differences between the institutions, institutional behaviours and practices which have been created in different socio-cultural contexts (Kostova 1999). This critical factor affects the ability of the expatriate's family to cope adequately with the ways in which things are done in another cultural and institutional context. Therefore, it seems plausible that the greater the distance between the "home" and "host" contexts, the lower the degree of the family's adaptation to its new environment. We believe that in such situations, the risk of failure in expatriation increases. It is thus crucial for the parent company to pay attention to supportive HRM practices that can be provided to expatriate families to help them cope with this risk in critical phases of the expatriation process.

In sum, there appears to be three specific critical phases in which the expatriate's family needs more urgent HRM support from the parent company than they will generally need during the expatriation process, namely, during the time of making the decision to go abroad, at the beginning of the expatriation process, and upon repatriation. It can then be deduced that the importance of the attribute of urgency varies according to the stage of the expatriation process. Moreover, we believe that the importance of the urgency attribute varies depending on the context of the expatriation: greater cultural (and institutional) distance(s) between the "host" and "home" contexts calls for more intensive attention from the parent company.

\section{Legitimacy}

Mitchell et al. (1997) argue that legitimacy refers to socially accepted and expected behaviours. It can be understood as conformity to social norms, values and expectations. According to Suchman's (1995) theory, legitimacy involves both the evaluative and the cognitive dimension. Entities are legitimate when they and their actions are desirable as well as understandable in the social environments in which they operate. Mitchell et al. (1997) draw upon Suchman's (1995, p. 574) definition of legitimacy as "a generalized perception or assumption that the actions of an entity are desirable, proper, or appropriate within some socially constructed system of norms, values, beliefs, and definitions." Legitimacy can be said to be a desirable social good that is shared rather than based on self-perception (Mitchell et al. 1997). Organizations as well as people who lose their legitimacy have difficulty in entering into social exchange processes, since their partners do not trust their compliance with accepted social norms, beliefs and values (Palazzo and Scherer 2006).

Suchman (1995) makes a distinction between three main types of legitimacy: pragmatic, cognitive, and moral legitimacy. Pragmatic legitimacy exists as long as the objectives and actions of the company are perceived as beneficial to and useful for its social constituents. Working and living in a foreign country has been shown to give rise to new challenges, and expatriates are known to suffer from stressors beyond those that most of their home-based peers experience (Shortland and Cummins 2007). A frequently neglected 
additional fact is that employees are confronted with new professional roles and cultures and find themselves under new hierarchical pressures or governed by rules they may not be familiar with (Bennett and Bennett 2004; Claus et al. 2011; Kim 2001; Nie and Lämsä 2015). The situation thus becomes even more complex and demanding when the expatriate has a family - a spouse and children who also need to adapt to a challenging expatriation situation and can suffer stress and problems in adjustment (Fischlmayr and Kollinger 2010; Mäkelä et al. 2011; Takeuchi 2010). For example, according to Tharenou (2008), family factors lead to more motivation problems for women than for men, with the result that women are expatriating less than men.

Stress theories suggest that stress arises when the demands and expectations of the environment exceed the individual's resources. Therefore, in order to manage stress it is essential for organizations to provide resources and support when demands are high (Lazarus 1993), as it is the case during an expatriation. It seems evident that both expatriates and their families will value the support provided by the parent company during their expatriation, since such support has been found to relate positively to cross-cultural adjustment, as the following research results show. For example, work-family and career-related support practices and logistical support for the family have been found to be a valuable and expected support during IAs (Lazarova and Caligiuri 2001; Mendenhall, Kühlmann, Stahl and Osland 2002; Selmer 1999). Consequently, it can be expected that pragmatic legitimacy is present in the relationship between the parent company and the expatriate's family in the sense that the supportive HRM activities are perceived as beneficial, desirable and useful by the expatriate family. They are expected from the company, since an IA is a significant and demanding experience for both the expatriate and her or his family.

Cognitive legitimacy is based on broadly shared taken-for-granted cultural values, beliefs and assumptions. Thus, it stems from the availability of cultural models, assumptions and conventions that provide credible explanations for the company's endeavors (Ashforth and Gibbs 1990). In general, due to global trends such as changing values regarding the importance of the work/life balance, individuals' professional decisions are increasingly influenced by family considerations in all organizational life (Greenhaus and Powell 2006). According to Hobson (2011), many European-level attitudinal surveys reveal that the majority of women and men regard work/life balance as their first priority when considering their workplace. Given the clear negative impact of work/life conflict on employees (Greenhaus and Beutell 1985; Hobson 2011) and the emerging evidence that work/life balance and enrichment have positive effects (Greenhaus and Powell 2006), organizations are increasingly expected to establish policies and practices aimed at assisting employees with managing the demands of work and life and supporting their wellbeing in general (Beauregard and Henry 2009). Moreover, because of changing values, which increasingly stress the importance of life balance as well as social relations and values in general (Inglehart 2000), particularly in many Western societies, it seems evident that employing organizations are expected to take these values into consideration in their HRM policies, practices and activities (e.g. employee branding). Consequently, to have cognitive legitimacy in its business and social environments the parent company needs to rely on these values and expectations in its HR management.

Finally, moral legitimacy is based on moral judgments about the goodness and rightness of the firm's actions and outputs. It reflects a positive normative evaluation and rests on judgments about whether the activity of the firm is "the right thing to do" (Suchman 1995, p. 579). Ashforth and Gibbs (1990, p. 177) argue that an organization is understood as morally legitimate if it pursues acceptable objectives in a socially acceptable manner. Seen from the moral legitimacy point of view, a satisfactory work-family relationship provides mutual benefits for the organization and its employees: when employees are better able to 
juggle their responsibilities thanks to support from the organization, a positive impact on employee wellbeing, performance and attitudes results (Bhattacharya, Sen and Korschun 2008; Beauregard and Henry 2009). Pitt-Catsouphes and Googins (2005) note that if work/life balance is seen as a part of CSR, businesses ought to focus on the quality of working life as well as on the quality of non-working life as a way of achieving organizational goals and increasing people's wellbeing. Furthermore, family-friendliness and related benefits may also be seen as a valuable public relations tool (Nord, Fox, Phoenix and Viano 2002), which can serve to improve the organization's image and reputation as an employer (Bhattacharya et al. 2008). For example, Cascio (2000) indicates that firms ranked highest on Working Mother magazine's "Best 100 companies for working mothers" list get twice as many job applications as firms that are not on the list.

Even though the preceding discussion stresses the instrumental value of CSR, for example, in terms of gaining or maintaining a reputation as a good employer, Carroll (1991) argues that ethical responsibilities are also a crucial part of CSR. Since various CSR-related HRM policies and practices such as support for work/life balance are nowadays increasingly expected from companies (Crane and Matten 2010; Freeman et al. 2010; Kujala 2010; Midttun et al. 2006), Carroll's (1991) argument suggests that even though the expatriate's family as a stakeholder needs to be taken into consideration by the company, the relationship cannot be based only on instrumental values but must be based also on the ethicality of CSR. This means that moral reasoning and legitimacy go beyond purely pragmatic and cultural considerations to encompass ethical concerns, and thus the ethical aspect of moral legitimacy merits consideration. Palazzo and Scherer (2006) also argue that although legitimacy has become a critical issue for companies, particularly those that operate internationally and globally, pragmatic and cognitive considerations alone no longer provide a solid basis for a firm's legitimacy and they need to be complemented by ethical claims to legitimacy.

Drawing upon the discussion in previous sections of power, urgency and legitimacy, we conclude that, in general, these three attributes are indeed present in the relationship between the expatriate's family and the parent company, and thus the expatriate's family can be regarded as a stakeholder of the parent company. However, what kind of a stakeholder the family is can vary depending on the parent company management's perception of the stakeholder's possession of one, two or all three of these attributes in the relationship. When only one attribute is perceived to be present, the salience of the stakeholder is low. When two attributes are present, salience is moderate, and when all three are present, stakeholder salience is high. Our discussion indicates that in the expatriate family-parent company relationship, the urgency attribute seems to be the most dynamic and to vary most dramatically across phases and contexts of expatriation. Consequently, we make three propositions:

Proposition 2: The stakeholder engagement between the expatriate's family and the parent company is moderate during the entire expatriation period, since two attributes - power and legitimacy - are present at all times in the relationship.

Proposition 3: The stakeholder engagement between the expatriate's family and the parent company is high in the beginning and at the end of the expatriation period, since at these points three attributes - power, legitimacy and urgency - are present in the relationship.

Proposition 4: The stakeholder engagement between the expatriate's family and the parent company is high in contexts characterized by a significant cultural (and institutional) distance between the home and host countries, since in such context(s) three attributes power, legitimacy and urgency - are present in the relationship. 


\section{Assessing the wellbeing of stakeholders}

The discussion above suggests that even if the theory of stakeholder salience (Mitchell et al. 1997) highlights the importance of various reasons in justifying HRM practices to advance the coping and success of the expatriate's family, the theory does not provide an explicit ethical justification of the practices. Therefore, we argue for the capabilities approach to make such a contribution. Indeed, Sen (1985) developed the capabilities approach as a framework for evaluating social outcomes across a variety of contexts. Rather than constituting a theory, this approach should perhaps be considered an evaluative framework for assessing the quality of life and wellbeing (Robeyns 2005). In this sense it is a particularly useful complement to the stakeholder approach elaborated above. In the words of Robeyns (2005, p. 94), the "capability approach is a broad normative framework for the evaluation and assessment of individual wellbeing and social arrangements". Although normative, the capabilities approach permits the assessment of heterogeneous preferences for different stakeholders. Hobson (2011, p. 148) captures this flexibility in the statement that "for Sen, the core issue is not only what individuals choose, but the choices that they would make if they had the capabilities to lead the kind of lives that they want to lead". Thus, Sen (1985) distinguishes between capabilities and functionings, which can be seen as the means and the end, respectively. Robeyns (2003) proposes that the difference between capabilities and functioning is like the difference between opportunities and outcomes, or between the freedom to achieve something and the achievement.

The capabilities approach suggests that, to the parent company that takes CSR seriously, the wellbeing and quality of life of the expatriate's family (and indeed of the expatriate him-/herself, too) should be an ethical imperative guiding the company's HRM policies and practices. This imperative is important not only for utilitarian reasons (for example, the costs when an IA is discontinued due to family issues) but also, and importantly, for non-utilitarian - social, developmental and moral - reasons (Robeyns 2005). In Sen's (1985) thinking, the traditional utilitarian notion of welfare and wellbeing covers only partially the true picture of wellbeing and quality of life, which should be viewed in terms of people's ability to do valuable acts and reach valuable states of being. Socially responsible HRM practices need to be evaluated in terms of their contribution to enriching and supporting the lives of the expatriate's family so that the family can achieve the wellbeing and quality of life that they value. The capabilities approach stresses that people should have the opportunity to do and be what they value (Robeyns 2005; Hobson 2011). Safety, social relations, cultural integration, health, free-time activities and the expatriate's chances of investing in family life are examples of capabilities (cf. Robeyns 2003) that can contribute to the functionings of the expatriate's family.

In sum, drawing on the capabilities approach (Sen 1985), it can be said that it is an ethical imperative for socially responsible HRM practices to take into consideration the expatriate's family needs and expectations and support their lives so that they can achieve wellbeing and a high quality of life in the expatriate environment. This not only means paying attention to and implementing various company-planned HRM practices, but calls too for the development and implementation of careful stakeholder dialogue between the company and the family, so that both partners have equal opportunities to make their expectations and aims heard and to bring them into the open in the process of planning, conducting and evaluating HRM practices.

Since expatriation often leads to a radical shift in family roles and living circumstances, at least in the short term, it is not reasonable to expect that family members (or indeed the expatriate her- or himself) can replicate all elements of their previous lives in 
the host country - socially, personally, economically or intellectually. Thus a more flexible framework for assessing outcomes is required. The capabilities approach provides an evaluative mechanism to maintain quality of life even if the functioning of the family members is different in the new context compared to the domestic employment scenario.

Another important distinction of the capabilities approach arises from the recognition that rights may not always lead to fulfilled preferences. Hobson (2011) describes an agency gap: individuals may have rights to undertake certain activities but may in fact be unable to exercise these rights - that is, they lack the capabilities to function accordingly. Hobson (2011) notes, by way of example, that an inadequate work/life balance may prevail in spite of legal provisions for flexibility in working times or for time off work. In the context of expatriation, relevant capabilities include the capability to function as a worker on the part of the expatriate's spouse, the capability to function as a parent on the part of the expatriate (who may be charged with an additional workload abroad) and, perhaps for both expatriate and spouse, the capability to function in a way that ensures a balanced career with a satisfactory equilibrium between the professional and familial spheres of life.

A particular advantage of the capabilities approach is the integration of gender equality early in the development of the approach. Sen (1985) recognized that wellbeing is the result of more than only market-based activities and thus established a clear role for care as a functioning and in the consideration of capabilities. Since expatriation remains highly gendered, this gender-sensitive dimension is particularly useful. Women remain underrepresented among international assignees (van der Velde, Bossink and Jansen 2005; Tharenou 2008), and consequently the spouses following expatriates are often female. However, the trailing male spouse is an emerging phenomenon.

The list of capabilities has been expanding as Sen's (1985) theory is applied to new domains. These "capabilities to function" provide a number of dimensions in which wellbeing can be assessed. Functionings range from adequate shelter and the preservation of life through to more subtle measures of the quality of life. Hobson (2011) suggests that work/life balance is also a functioning. Robeyns (2003) proposes a wide range of capabilities in her assessment of the capabilities approach applied to gender equality - life and physical health, mental wellbeing, bodily integrity and safety, social relations, political empowerment, education and knowledge, social reproduction and non-market care, paid work and other projects, shelter and environment, mobility, leisure activities, time-autonomy, respect, religion and spirituality. Each of these is of some relevance to the expatriation process, and their broad scope helps to capture the multiple ways in which an IA impacts on the lives of expatriates and their families.

Consequently, based on the above discussion, we make the following additional propositions:

Proposition 5: A parent organization that takes a holistic perspective on well-being will give greater consideration to the capabilities required for the expatriate family to "be" or function in its HRM policy and practice

Proposition 6: Socially responsible HRM practices developed in a stakeholder dialogue between the parent company and the expatriate's family can advance the functioning of the expatriate's family.

Furthermore, the capabilities approach is particularly well suited to dealing with change, and capabilities and functioning permit a dynamic analysis of personal wellbeing. Authors such as Hobson (2011) have suggested that the capabilities approach can evaluate changing expectations of life satisfaction as women's and men's roles change in society - women's expectations of work are changing, as are men's of parenting. Traditional gender relations 
have constituted one of the greatest challenges to expatriation and to decisions to accept international assignments (Coles and Fechter 2008). The capabilities approach accommodates heterogeneity among people, since individuals have different aspirations to "be" or "function". The capabilities required to achieve these states (and therefore positive wellbeing outcomes) inherently include a capacity for change created by a changing environment and new opportunities. This contextual flexibility of Sen's (1985) approach is particularly relevant for IAs, given that the change in context is a key element.

\section{Conclusion}

In this article we argued for the recognition of the expatriate's family as the firm's stakeholder in an IA. We showed why the expatriate's family can be considered a stakeholder of the parent company and what kind of a stakeholder the family is. We also argued that the parent company needs to develop and apply a holistic wellbeing orientation to show stakeholder responsibility in its HRM practices and CSR in general in the IA arena.

We also offer an innovative theoretical framework and a series of propositions to enrich and broaden traditional perspectives on expatriation. This framework and propositions enable future empirical investigation of the expatriate's family as a stakeholder of the firm. The combination of the stakeholder salience theory and the capabilities approach in expatriation research, employed here, makes it possible to consider the family's role in expatriation in both research and practice more explicitly and accurately than has been done before. From the practical point of view, such a framework provides guidelines for companies that take their stakeholder responsibilities seriously, view them as strategically important and regard them as key to their HRM strategy and practices. The framework offers the advantage of recognizing the role of the family in any expatriate recruitment decision and during the assignment. From the viewpoint of expatriation research, our approach also provides a dynamic and detailed conceptualization of the family as a stakeholder in IAs.

However, it is also important to recognize that the explicit recognition of the family as a company stakeholder may also create tensions, since the formal employment relationship continues to be between the employee and the employer. Even though previous research on expatriation has paid attention to the work-family relationship (e.g. Caligiuri et al. 1998; Dupuis et al. 2008; Haslberger and Brewster, 2008; Mäkelä et al. 2011; Shaffer and Harrison 1998; Smith and Tornikoski 2012), very few studies on the work-family relationship have considered the significance of the family (Heikkinen, Lämsä and Hiillos 2014). A limitation of our research is that it ignores the diversity of families and of their members, who may have different roles in expatriation. We suggest that a more nuanced view of the family is necessary in future studies. For example, in the context of IAs, the functioning (Sen 1985) of spouses, children and other family members as well as of the expatriates themselves may vary. This is a topic which requires more investigation in the future using a wider lens for expatriate research that considers families as stakeholders and their capabilities to function in new environments.

\section{References}

Adler, P.S. (1975), 'The Transitional Experience: An Alternative View of Culture Shock', Journal of Humanistic Psychology, 15(4), 13-23.

Ali, A., Van der Zee, K.I., and Sanders, G. (2003), 'Determinants of Intercultural Adjustment among Expatriate Spouses', International Journal of Intercultural Relations, 27(5), 563580 . 
Ashforth, B.E., and Gibbs, B.W. (1990), 'The Double-Edge of Organizational Legitimation', Organization Science, 1(2), 177-194.

Banai, M., and Harry, W. (2004), 'Boundaryless Global Careers: The International Itinerants', International Studies of Management and Organization, 34(3), 96-120.

Beauregard, T.A., and Henry, L.C. (2009), 'Making the link between work-life balance practices and organizational performance', Human Resource Management Review, 19(1), 9-22.

Bennett, J.M., and Bennett, M.J. (2004), 'Developing Intercultural Sensitivity. An Integrative Approach to Global and Domestic Diversity', in Handbook of Intercultural Training (3rd ed.), eds. D. Landis, J.M. Bennett and M.J. Bennett, Thousand Oaks, CA: Sage, pp. $147-165$.

Bhattacharya, C.B., Sen, S., and Korschun, D. (2008), 'Using Corporate Social Responsibility to Win the War for Talent', MIT Sloan Management Review, 49(2), 36-44.

Black, J.S., Mendenhall, M., and Oddou, G. (1991), 'Toward a Comprehensive Model of International Adjustment: An Integration of Multiple Theoretical Perspectives', Academy of Management Review,16(2), 291-317.

Brett, J.M., and Stroh, L.K. (1995), 'Willingness to Relocate Internationally', Human Resource Management, 34(3), 405-424.

Caligiuri, P.M., Hyland, M.M., Joshi, A., and Bross, A.S. (1998), 'Testing a Theoretical Model for Examining the Relationship between Family Adjustment and Expatriates' Work Adjustment', Journal of Applied Psychology, 83(4), 598-614.

Carroll, A.B. (1991), 'The Pyramid of Corporate Social Responsibility: Toward the Moral Management of Organizational Stakeholders', Business Horizons, 34(4), 39-48.

Cascio, W.F. (2000), Costing Human Resources: The Financial Impact of Behavior in Organizations (4th ed.), Cincinnati, OH: South-Western College Publishing.

Claus, L., Lungu, A.P., and Bhattacharjee, S. (2011), 'The Effects of Individual, Organizational and Societal Variables on the Job Performance of Expatriate Managers', International Journal of Management, 28(1), 249-271.

Coles, A. and Fechter, A-M. (2008) 'Gender and Family among Transnational Professionals', New York: Routledge.

Crane, A., and Matten, D. (2010), Business Ethics: A European Perspective (3rd ed.), Oxford: Oxford University Press.

Donaldson, T., and Preston, L.E. (1995), 'The Stakeholder Theory of the Corporation: Concepts, Evidence, and Implications', Academy of Management Review, 20(1), 65-91.

Dowling, P.J., and Welch, D.E. (2004), International Human Resource Management: Managing People in a Multinational Context (4th ed.), London: Thomson. 
Dupuis, M.-J., Haines, V.Y., and Saba, T. (2008), 'Gender, Family Ties, and International Mobility: Cultural Distance Matters', International Journal of Human Resource Management, 19(2), 274-295.

Etzioni, A. (1964), Modern Organizations, Englewood Cliffs, NJ: Prentice-Hall.

Fischlmayr, I.C., and Kollinger, I. (2010), 'Work-Life Balance - A Neglected Issue among Austrian Female Expatriates', International Journal of Human Resource Management, 21(4), 455-487.

Freeman, R.E. (1984), Strategic Management: A Stakeholder Approach, Boston: Pitman.

Freeman, R.E., Harrison, J.S., Wicks, A.C., Parmar, B., and de Colle, S. (2010), Stakeholder Theory: The State of the Art, Cambridge: Cambridge University Press.

Greenhaus, J.H., and Beutell, N.J. (1985), 'Sources of Conflict between Work and Family Roles', Academy of Management Review, 10(1), 76-88.

Greenhaus, J.H., and Powell, G.N. (2006), 'When Work and Family Are Allies: A Theory of Work-Family Enrichment', Academy of Management Review, 31(1), 72-92.

Harvey, M. (1998), 'Dual-Career Couples during International Relocation: The Trailing Spouse', International Journal of Human Resource Management, 9(2), 309-331.

Haslberger, A., and Brewster, C. (2008), 'The Expatriate Family: An International Perspective', Journal of Managerial Psychology, 23(3), 324-346.

Heikkinen, S., Lämsä, A.-M., and Hiillos, M. (2014), 'Narratives by Women Managers about Spousal Support for Their Careers', Scandinavian Journal of Management, 31(1), 27-39.

Hill, C.W.L., and Jones, T.M. (1992), 'Stakeholder-Agency Theory', Journal of Management Studies, 29(2), 131-154.

Hobson, B. (2011), 'The Agency Gap in Work-Life Balance: Applying Sen's Capabilities Framework within European Contexts', Social Politics, 18(2), 147-167.

Hofstede, G. (1991), Cultures and Organizations: Software of the Mind, London: McGrawHill.

Inglehart, R. (2000), 'Globalization and Postmodern Values', Washington Quarterly, 23(1), 215-228.

Kauppinen, M. (1994), Antecedents of Expatriate Adjustment: A Study of Finnish Managers in the United States, Helsinki: Helsinki School of Economics Press.

Kim, Y.Y. (2001), Becoming Intercultural: An Integrative Theory of Communication and Cross-Cultural Adaptation, Thousand Oaks, CA: Sage. 
Kramar, R. (2014), 'Beyond strategic human resource management: is sustainable human resource management the next approach?', The International Journal of Human Resource Management, 25(8), 1069-1089.

Kujala, J. (2010), 'Corporate Responsibility Perceptions in Change: Finnish Managers' Views on Stakeholder Issues from 1994 to 2004', Business Ethics: A European Review, 19(1), 14-34.

Lauring, J., and Selmer, J. (2010), 'The Supportive Expatriate Spouse: An Ethnographic Study of Spouse Involvement in Expatriate Careers', International Business Review, 19(1), 59-69.

Lazarova, M., and Caligiuri, P. (2001), 'Retaining Repatriates: The Role of Organizational Support Practices', Journal of World Business, 36(4), 389-401.

Lazarova, M., Westman, M., and Shaffer, M.A. (2010), 'Elucidating the Positive Side of the Work-Family Interface on International Assignments: A Model of Expatriate Work and Family Performance', Academy of Management Review, 35(1), 93-117.

Lazarus, R.S. (1993), 'From Psychological Stress to the Emotions: A History of Changing Outlooks', Annual Review of Psychology, 44, 1-21.

Mäkelä, L., Suutari, V., and Mayerhofer, H. (2011), 'Lives of Female Expatriates: Work-Life Balance Concerns', Gender in Management, 26(4), 256-274.

Mendenhall, M., Kühlmann, T.M., Stahl, G.K., and Osland, J.S. (2002), 'Employee Development and Expatriate Assignments', in The Blackwell Handbook of CrossCultural Management, eds. M.J. Gannon and K.L. Newman, Oxford: Blackwell, pp. 167-183.

Midttun, A., Gautesen, K., and Gjølberg, M. (2006), 'The Political Economy of CSR in Western Europe', Corporate Governance, 6(4), 369-385.

Mitchell, R.K., Agle, B.R., and Wood, D.J. (1997), 'Toward a Theory of Stakeholder Identification and Salience: Defining the Principle of Who and What Really Counts', Academy of Management Review, 22(4), 853-886.

Näsi, J. (ed.) (1995), Understanding Stakeholder Thinking, Helsinki: LSR-julkaisut.

Nie, D. and Lämsä, A-M. (2015), 'The Leader-Member Exchange Theory in the Chinese Context and the Ethical Challenge of Guanxi', Journal of Business Ethics, 128(4), 851861.

Nord, W.R., Fox, S., Phoenix, A., and Viano, K. (2002), 'Real-World Reactions to Work-Life Balance Programs: Lessons for Effective Implementation', Organizational Dynamics, 30(3), 223-238.

Oberg, K. (1958), Culture Shock and the Problem of Adjustment to New Cultural Environment, Washington, D.C.: Department of State. 
Paauwe, J. and Richardson, R. (1997), 'Introduction special issue on HRM and performance', International Journal of Human Resource Management, 8(3), 257-262.

Palazzo, G., and Scherer, A.G. (2006), 'Corporate Legitimacy as Deliberation: A Communicative Framework', Journal of Business Ethics, 66(1), 71-88.

Pitt-Catsouphes, M., and Googins, B. (2005), 'Recasting the Work-Family Agenda as a Corporate Social Responsibility', in Work and Life Integration: Organizational, Cultural, and Individual Perspectives, eds. E.E. Kossek and S.J. Lambert, Mahwah, NJ: Erlbaum, pp. 469-490.

Riusala, K., and Suutari, V. (2000), 'Expatriation and Careers: Perspectives of Expatriates and Spouses', Career Development International, 5(2), 81-90.

Robeyns, I. (2003), 'Sen's Capability Approach and Gender Equality: Selecting Relevant Capabilities', Feminist Economics, 9(2-3), 61-92.

Robeyns, I. (2005), 'The Capability Approach: A Theoretical Survey', Journal of Human Development, 6(1), 93-114.

Schneider, M. (2002), 'A Stakeholder Model of Organizational Leadership', Organization Science, 13(2), 209-220.

Selmer, J. (1999), 'Career Issues and International Adjustment of Business Expatriates', Career Development International, 4(2), 77-87.

Sen, A.K. (1985), Commodities and Capabilities, Oxford: Elsevier.

Shaffer, M.A., and Harrison, D.A. (1998), 'Expatriates' Psychological Withdrawal from International Assignments: Work, Nonwork, and Family Influences', Personnel Psychology, 51(1), 87-118.

Shaffer, M.A., Harrison, D.A., Gilley, K.M., and Luk, D.M. (2001), 'Struggling for balance amid turbulence on international assignments: work-family conflict, support and commitment', Journal of Management, 27(1), 99-121.

Shortland, S., and Cummins, S. (2007), 'Work-Life Balance: Expatriates Reflect the International Dimension', Global Business and Organizational Excellence, 26(6), 28-42.

Siljanen, T., and Lämsä, A.-M. (2009), 'The Changing Nature of Expatriation: Exploring Cross-Cultural Adaptation through Narrativity', International Journal of Human Resource Management, 20(7), 1468-1486.

Smith, M., and Tornikoski, C. (2012), 'Ethical Issues for International Human Resource Management: The Case of Recruiting the Family?', in Business Ethics - A Critical Approach: Integrating Ethics across the Business World, eds. P. O'Sullivan, M. Smith and M. Esposito, Abingdon: Routledge, pp. 317-331.

Suchman, M.C. (1995), 'Managing Legitimacy: Strategic and Institutional Approaches', Academy of Management Review, 20(3), 571-610. 
Suutari, V., and Brewster, C. (2000), 'Making Their Own Way: International Experience through Self-Initiated Foreign Assignments', Journal of World Business, 35(4), 417-436.

Suutari, V., Tornikoski, C., and Mäkelä, L. (2012), 'Career Decision Making of Global Careerists', International Journal of Human Resource Management, 23(16), 3455-3478.

Takeuchi, R. (2010), 'A Critical Review of Expatriate Adjustment Research through a Multiple Stakeholder View: Progress, Emerging Trends, and Prospects', Journal of Management, 36(4), 1040-1064.

Takeuchi, R., Yun, S., and Tesluk, P.E. (2002), 'An Examination of Crossover and Spillover Effects of Spousal and Expatriate Cross-Cultural Adjustment on Expatriate Outcomes', Journal of Applied Psychology, 87(4), 655-666.

Tharenou, P. (2008), 'Disruptive decisions to leave home: Gender and family differences in expatriation choices', Organizational Behavior and Human Decision Processes, 105, 183-200.

Ward, C., Bochner, S., and Furnham, A. (2001), The Psychology of Culture Shock (2nd ed.), Hove, East Sussex: Routledge.

van der Velde, M. E., Bossink, C. J., and Jansen, P. G. (2005), 'Gender differences in the determinants of the willingness to accept an international assignment', Journal of Vocational Behavior, 66(1), 81-103. 